\title{
Chinese Reform and Practice of Violin Playing Teaching in Music Colleges
}

\author{
Wenjia Li \\ College of Music, Zhaoqing University, Guangdong, Zhaoqing, China, 526061 \\ Keywords: violin; performance teaching; Chinese reform \\ Abstract: The violin is produced in Europe and is recognized by the world as one of the \\ most important Western musical instruments. It enjoys the reputation of "Queen of Musical \\ Instruments". Since it was introduced to China, it has deeply influenced the music and \\ cultural life of our people and accelerated the development of the violin. At present, many \\ colleges and universities offer violin teaching courses, and the number of students \\ majoring in violin is increasing. Based on this, this paper conducts an in-depth analysis of \\ the current reform trend and current situation of violin-playing teaching in colleges and \\ universities in China, and proposes a new reform idea.
}

\section{Introduction}

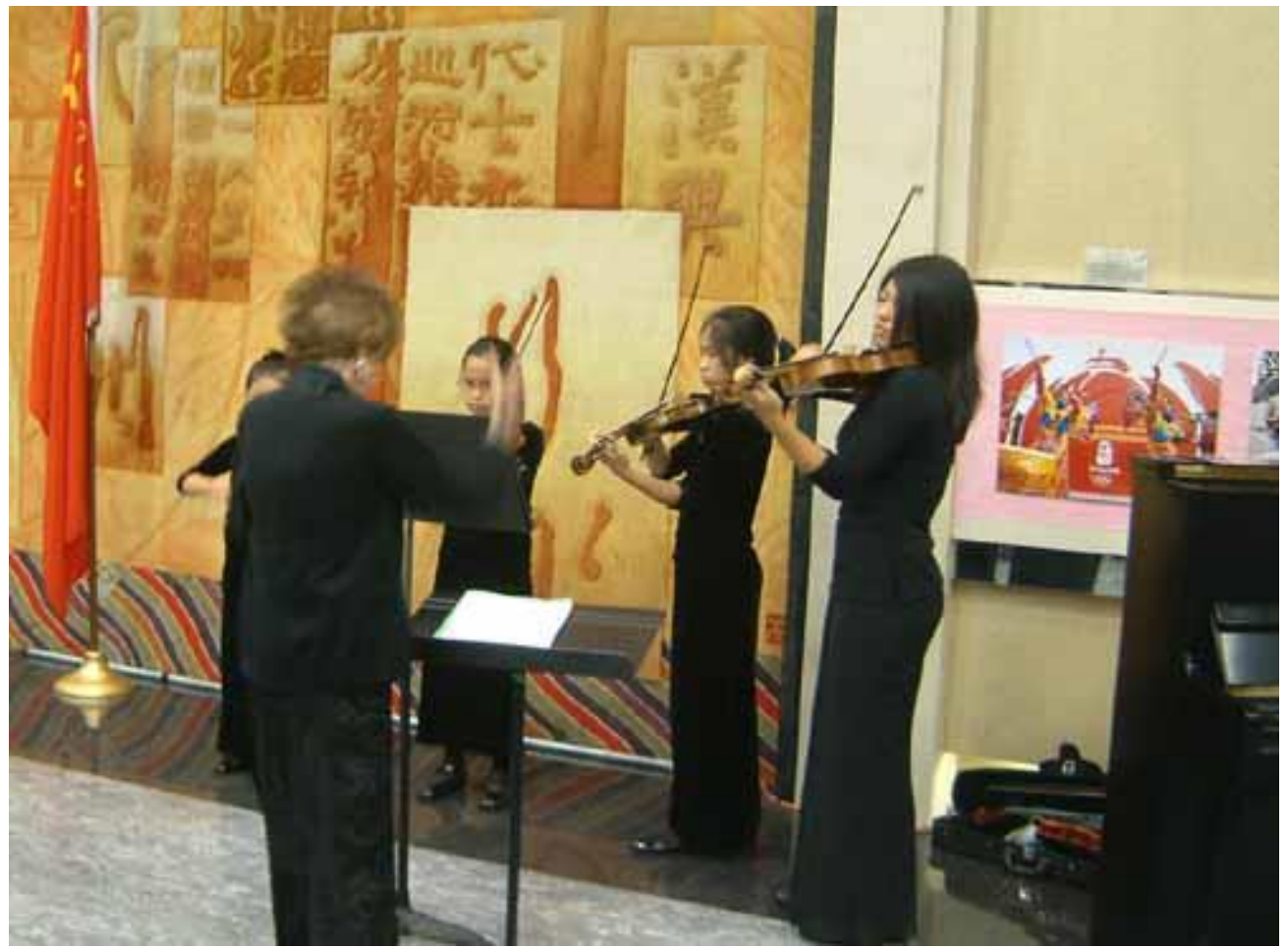

Figure 1: Musical college violin playing teaching 
During the reign of emperor Kangxi of the Qing dynasty, the violin was brought into China by missionaries. This Western musical instrument began to take root in the cultural soil of China. Over time, the violin-related performance techniques, composition techniques and music theory were introduced into China. Since the 21st century, China's social economy has developed rapidly, and the social form has gradually changed. Various universities have set up violin courses. Violin education has shown a rapid development trend and achieved good results. However, from the actual situation of violin performance teaching in various universities in China, there are still many problems. Students are unable to deeply understand the violin culture and fail to realize the importance of the development of the violin sinicization, which plays an important role in inheriting and developing the traditional culture of the Chinese nation. Therefore, it is necessary to strengthen the research on the Chinese reform of the violin playing teaching in colleges and universities in order to promote the development of music culture in China ${ }^{[1]}$.

\section{The necessity of the reform and development of the teaching of violin performance in colleges and universities}

Since the reform and opening up, the level of social life has gradually improved, and people's emphasis on music culture in daily life has not only improved, but also promoted the development and progress of violin music, and closely integrated with traditional music culture in China. In recent years, many Western foreign musical instruments have been widely used in China. The violin has become an indispensable part of Chinese music culture, and many excellent Chinese musical works have been inherited to enrich our country's music and art fields. It was because of the introduction of the violin that it promoted the production of the traditional Chinese musical instrument Gao $\mathrm{Hu}$. Lu Wencheng, a famous Chinese musician, once combined the violin sound and the erhu sound, and finally gave birth to the traditional instrument of Gaohu. At the same time, the folk songs such as "Liang Zhu" and "The Pastoral" which are popular in China are all violin collaboration songs, which are the product of the perfect combination of traditional national songs and national diplomatic rhetoric. Therefore, the violin structure is very unique, which can bring unique creative thinking to Chinese traditional musical instruments and enrich the charm and artistic conception of Chinese traditional music culture. Therefore, in order to promote the rapid development of violin music, we must accelerate the reform of the Chinese teaching of violin teaching ${ }^{[2]}$.

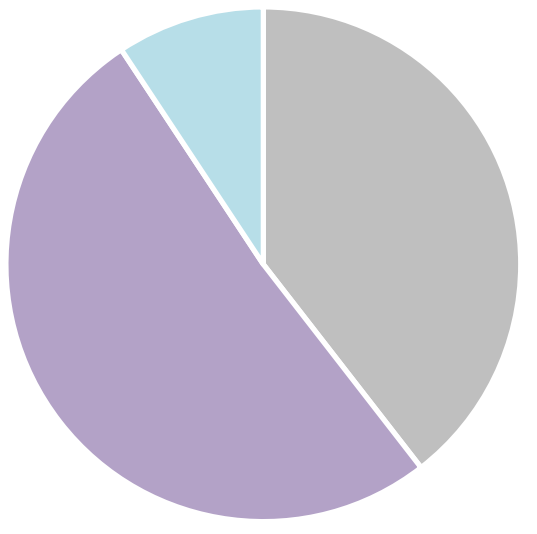

- Love Chinese violin $\quad$ Love Western violin

Disinclination for violin

Figure 2: Analysis of the popularity of two different violins 
At present, the violin music art has been initially integrated with traditional Chinese music and shows a unique musical charm. However, in today's economic and cultural diversification, the demand for talent in the music market is constantly expanding. As an important base for music talent cultivation, universities and colleges must shoulder the responsibility of cultivating talents of violin music. In universities and colleges, it is necessary to rapidly popularize music of Chinese violin in order to better develop the traditional excellent music culture and realize the wide spread and inheritance of Chinese music culture.

\section{The Status quo of Chinese reform of violin teaching in colleges and universities}

With the development of the times, the current level of violin art in China has gradually approached the Western level, so the violinization of China has achieved good results. With the rapid development of cultural global integration, the traditional music of the Chinese nation has gradually collided with Western music culture, which has also diversified the development of traditional Chinese music style. In recent years, China has successively appeared a series of classic violin works such as "Difficulties in Traveling", "Homesickness" and "Fishing Boat Singing Evening", which also shows that the music and art culture in our country is constantly enriched ${ }^{[3]}$.

However, on the other hand, in the teaching of violin playing in major institutions of higher learning, the teaching repertoire used in it gradually presents a western style, and the emphasis on Chinese violin works is decreasing, and there is no emphasis on playing Chinese violin works, resulting in Many students are not familiar enough with Chinese violin works, and they don't even know which classics are there. Only in order to cope with exams or graduation performances will they be slightly exposed to Chinese violin music. In the long run, it will lead to the separation of violin teaching and social development in colleges and universities, which is not conducive to the inheritance of the traditional music culture of the Chinese nation.

\section{Thoughts on the reform of Chinese violin teaching in colleges and universities}

With the integration of the global economy and culture, the demand for violin players in the society is constantly expanding. In the teaching of violin performance, colleges and universities must pay attention to the reform of China, strengthen the cultivation of violinist talents in China, and adapt to the development of music culture in the future. Specifically, the author proposes such a few points:

\subsection{Holding violin competitions}

First, the violin professional teachers of the Conservatory of Music negotiated and coordinated the repertoire, and held several Chinese works competitions within a certain range. China's excellent violin music works are rich in traditional Chinese cultural heritage. They have influenced generations of Chinese children in the process of inheritance, and have profound significance in shaping the value of individuality in the development of Chinese art. Through the form of competition, more teachers and students will be exposed to China's excellent traditional music works, and these works will spread more widely in music colleges. In teaching and performance occasions, the increase of Chinese music works not only enhances the cultural heritage of the educators and performers, but also enables them to serve as a medium of communication for these outstanding Chinese music to enter more people's horizons ${ }^{[4]}$. 


\subsection{Held several concerts of Chinese violin music works}

Second, a number of concerts of Chinese violin music works were held at the annual school music and culture week. The former music academies have successfully held related concerts, but due to the small openness of the venue, the performers and listeners are all teachers and students of the music school. It is now possible to take the annual academy music week in a form that is open to the whole society and free of votes. At that time, many masters and listeners who love music in the society will participate. During the music week, while encouraging the teachers and students of the school to perform Chinese violin music, they invited domestic and foreign musicians and teachers and students to participate in the concert of Chinese violin music works. As a result, the music school teachers and students and those who love music in the society can Listening to high-quality Chinese excellent violin music works, the spread of these works has been extended from music colleges to society. At the time when the whole society attaches great importance to the development of literature and art, the implementation of this measure, while promoting Chinese violin music works, also plays an important role in promoting the inheritance and development of social excellent traditional culture.

\subsection{Increase the proportion of Chinese violin works}

Third, trying to increase the proportion of Chinese violin works in the student graduation exam. Nowadays, in many professional music schools or school music departments, the common trend of orchestral performance is inclined to western works. Most people have the idea that western Musical Instruments should play western music. However, there are undoubtedly some improper ideas. Although western orchestral instruments were introduced into China from the west, their development would be meaningless if they were separated from the traditional Chinese culture. Only when western excellent works are combined with traditional Chinese music works can the development of western Musical Instruments show its value ${ }^{[5]}$.

\section{Conclusions}

In general, the reform and practice of Chinese violin teaching and playing in China's music academy is of profound significance. Only with solid foundation can we have stable development. This reform can not only effectively promote the comprehensive development of the violin music culture, but also promote the rapid growth and progress of the violin industry in China. In addition, through the reform of violin performance teaching in music colleges and universities in China, we will vigorously develop the traditional Chinese violin teaching career, and strengthen our sense of identity and love for our national music culture. In this way, more inheritors of Chinese violin tradition music will be produced, thus promoting the sustainable development of Chinese music culture.

\section{References}

[1] Gao Fang. Exploring the reform and innovation of violin playing teaching [D]. Tianjin Conservatory of Music, 2012.

[2] Chen Wei. Research on the Status Quo and Reform of Violin Teaching in Colleges and Universities[J]. China Education Journal, 2015(s1).

[3] Peng Song. It is better to teach fish than to teach fish--the quality of practicing piano in professional violin teaching[J]. Music Creation, 2012(10):185-187.

[4] Chen Wei. A Probe into the Reform and Innovation Strategy of Violin Teaching in Colleges and Universities[J]. China Science and Technology Expo, 2014(5): 414-414.

[5] Guo Zhelong. On the Nationalization of Violin Chinese Works in Teaching[D]. Guizhou Normal University, 2014. 